\title{
Further Thoughts on Talking to the Unreasonable: A Response to Wong
}

\author{
Matthew Clayton ${ }^{1} \cdot$ David Stevens ${ }^{2}$
}

Published online: 5 February 2019

(c) The Author(s) 2019

\section{Introduction}

In 'When God Commands Disobedience' (Clayton and Stevens 2014) we address the question of how Rawlsian political liberals should treat the religiously unreasonable. The religiously unreasonable are those who, for reasons of religious faith or perceived divine command, reject one or more of the fundamental principles of society as a cooperative enterprise between free and equal people, and who may seek to change (or even punish) the political community in line with their comprehensive religious beliefs. We argue, first, that political liberals have weighty reasons to engage with the unreasonable. However, second, following Hobbes (1991) in observing that divine law trumps law enacted by humans, we argue that the response to those who claim to have theistic reasons for acts that are unreasonable by liberal standards must be a theological one: political liberals must be prepared to offer a direct religious response. They must offer reasons aimed at establishing that the unreasonable are mistaken about the political implications of their religious doctrine or about the soundness of the particular religious doctrine they affirm. We then further elaborate the nature of the proper religious response by defending a division of justificatory labour with respect to who should engage the religiously unreasonable on such matters. We argue that politicians and political philosophers are not best placed to offer religious arguments. The danger would be that politicians and political philosophers risk, on the one hand, appearing sectarian if they commit publicly to a particular religious view, thus risking alienating other, reasonable, citizens of faith, or (on the other hand) they risk appearing disingenuous by offering conditional responses about what others should believe about their faith (but which

Matthew Clayton

m.g.clayton@warwick.ac.uk

David Stevens

David.Stevens@nottingham.ac.uk

1 Department of Politics and International Studies, Warwick University, Coventry CV4 7AL, UK

2 School of Politics and International Relations, University of Nottingham,

Nottingham NG7 2RD, UK 
they themselves do not in fact believe). Instead, we argue that the task of offering religious reasons would best be delegated to citizens themselves, particularly those reasonable citizens who share the same broad faith as those whom we hope to convince. Such reasonable citizens are not subject to the same worries over alienation and disingenuousness, or at least not to the same degree.

In his reply, Wong (2018) takes issue with our view of the division of justificatory labour. Whilst Wong agrees with our argument for the need for a religious response to the religiously unreasonable, he disagrees that the division of labour we propose is warranted. He argues that we are too pessimistic in thinking that politicians and political philosophers are incapable of conditional or conjectural reasoning in the same way as reasonable religious citizens. Wong contends that an appropriately framed form of argument from conjecture-one that is sincere in the sense of being both honest in its intentions and open-minded-can escape the dilemma of alienation and disingenuousness.

We are grateful to Wong for his challenge to our argument for a division of justificatory labour. We will take the opportunity to set out in a little more detail our conception of how political liberals ought to engage with politically unreasonable religious individuals, and in doing so offer our response to his criticisms.

\section{Belief Formation and Persuasion}

We begin with some clarifications regarding the moral principles regulating beliefformation, as well as the various strategies for persuasion. The purpose of engagement with politically unreasonable religious individuals (hereafter, the unreasonable) is to persuade them to change their beliefs such that their comprehensive religious convictions become consistent with liberal political principles. There are at least two weighty reasons to take steps to encourage the unreasonable to change their beliefs. First, it is valuable for our fellow citizens to come to see the worth of living in a society regulated by liberal principles because it makes their lives as citizens go better. Evangelizing on behalf of liberal society might, therefore, be done out of a concern for our fellow citizens (Rawls 1996; Dworkin 2011, Ch. 9). Second, liberal principles require us to prevent social disruption or harm to others and one way of effecting that is by persuading unreasonable citizens of the benefits of living in a stable and flourishing liberal democracy.

Persuading individuals to bring their comprehensive convictions into line with liberal principles is generally preferable to other forms of belief formation or manipulation of people's behaviour. Of course, it is possible to alter the payoffs of the various options available to someone (either by threats or incentives) such that, given her beliefs, she is led to behave differently; it is possible to 'nudge' people towards the right views or conduct by altering certain features of the choice architecture to shape their beliefs or behaviour; it may even become possible to change beliefs via direct neurointerventions into the brain (Clayton and Moles 2018). However, other things equal, persuasion is generally preferable to these other kinds of intervention because it leaves the individual free to come to see for herself that there are weighty reasons to endorse and live by liberal values. (Of course, if persuasion is ineffective, 
other techniques of belief-formation and conduct-regulation, such as nudging or neurointerventions might be explored.)

Suppose, then, that liberal societies are duty-bound to seek to convert the unreasonable to reasonable views by persuasion. It is important to explore how the burdens of persuasion ought to be distributed. It might be thought that all reasonable persons share in this burden equally, given their participation in, and the benefits they receive from, the liberal political community. However, even if the moral requirement is, in principle, universal in this way, we might think the duty better discharged by some specific person or persons on behalf of the political community (perhaps with compensation from others for costs incurred). Such persons might include politicians and public officials, those with particular expertise in religious and moral knowledge, or reasonable citizens of faith. Given that many, if not most people, will lack sufficient specialist knowledge to engage in the task of such persuasion, some form of division of labour seems most beneficial.

If a division of justificatory labour is justifiable, then it is a further question which actors or group of actors are best suited to act as liberal persuaders. This, in turn, will dictate what kinds of persuasion or arguments will be optimal. Here we might conceive of the possibilities as falling into two broad camps: those external to the particular religious tradition or doctrine held by those whom we are attempting to persuade; those internal to that tradition, in that they share some (or all) of the basic premises of the faith held by those whom we seek to persuade. ${ }^{1}$ For example, in an attempt to persuade, say, adherents of a version of Christianity who reject one or more of the fundamental principles of liberal political morality that their interpretation of the faith is mistaken, internal persuaders would include, predominantly, other Christian citizens who share similar presuppositions or articles of faith. External persuaders, by contrast, would lack this shared set of presuppositions or beliefs, and reasoning would, as we argue in our earlier piece, likely take place on a conditional or conjectural basis. Those who may undertake this task externally would include politicians and public officials, political philosophers, and citizens of other (and no) faiths.

As an example of such an internal reformatory interpretation of a religious doctrine aimed at participating in an overlapping consensus on a liberal constitutional regime, Rawls cites the work of Abdullahi Ahmed An-Na'im (1990). We discuss this example from Rawls in our original article. As Rawls writes, for An-Na'im's 'interpretation to be accepted by Muslims, it must be presented as the correct and superior interpretation of Shari'a' (Rawls 1999, p. 590, n. 46). An-Na' im begins his attempt at liberal persuasion from an acceptance of the truth of Shari'a law and the Islamic faith.

The external persuader, by contrast, offers arguments based on premises that the conjecturer does not herself accept. Instead, she attempts to construct an argument from the point of view of a comprehensive conception she does not share, in order to persuade her unreasonable interlocutor that, on the basis of his view, he should endorse a liberal political morality. As illustration, Wong uses the 2015 address of

\footnotetext{
1 See Schwartzman (2012) for a similar distinction between internal and external positions (esp. 534539).
} 
Bernie Sanders to the evangelical Christian institution, Liberty University. Whilst declaring his own position as that of a secularized Jew, Sanders argued that, from a Christian perspective, income inequality should be seen as one of the greatest moral issues of our time, and quoted New Testament passages in support of his interpretation of Christian requirements (see Wong 2018). Similarly, March (2009) provides another version of reasoning by conjecture, as a political philosopher who seeks to construct an interpretation of Islam conducive to forming an overlapping consensus on liberal political values and institutions.

We do not disagree with Wong (or Rawls) that external conjectural reasoning might be successful. However, which particular strategy is more likely to succeed is an empirical question, the best answer to which is one that is appropriately sensitive to various moral, social and political considerations. We argue that a division of justificatory labour that emphasizes internal engagement is, given those considerations, the optimal strategy.

\section{Conjecture: Between Fact and Perception}

To see why a strategy of internal engagement might be favoured over external conjectural reasoning, we might note a number of difficulties that the latter faces, but which are not faced—or faced to a lesser extent—by the former.

Persuasion by way of conjectural reasoning is a form of conditional argument, as we have seen. As Rawls states: 'we argue from what we believe, or conjecture, are other people's basic doctrines, religious or secular, and try to show them that, despite what they might think, they can still endorse a reasonable political conception that can provide a basis for public reasons' (Rawls 1999, p. 594). Our view is that when such conjectural reasons are offered by those external to a given religious doctrine, their motives may appear disingenuous to those whom they are trying to convince. This may be the case because such conjecturers are likely to be viewed as employing such a mode of reasoning for instrumental purposes. Or, such conjecturers might be viewed as closed-minded-entering the discussion with, say, a pre-conceived liberal-favouring interpretation of religious scripture. The unreasonable are unlikely to be persuaded by those whose motives they view with suspicion. Internal persuaders, by contrast, are less likely to encounter such degrees of suspicion on these counts.

Wong's view is that an appropriately framed form of conjectural reasoning is capable of being both honest and open-minded. Politicians and political philosophers who engage in conjecture must meet two jointly sufficient conditions. First, they should disclose their own actual beliefs (including their rejection of the beliefs held by the unreasonable) as well as their intentions for engaging in conjectural reasoning. This meets the condition for honesty. Second, they must be genuinely open to the possibility of revising their own views-even the possibility of abandoning their own reasonable liberal views-in light of compelling reasons or evidence as 
part of that discussion. Not holding one's views dogmatically, but being open to the possibility of change, meets the condition of open-mindedness. ${ }^{2}$

Our disagreement with Wong here is not about what would constitute conjectural reasoning, properly understood. Anyone who deliberately concealed their beliefs or intentions, or who was not open to the possibility of being wrong, would be reasoning in bad faith, and not engaged in the enterprise of reasoning from conjecture. As political liberals we should want citizens to be supportive of liberal political values and institutions for the right reasons, not through sleight of hand, or manipulation. However, our original claim is that even if the conjecturer is sincere in her enterprise, there is no guarantee that those to whom such remarks and arguments are addressed will view them as sincere-we are, by hypothesis, in the realm of non-ideal theory. Whilst Wong's remarks help clarify what properties conjectural reasoning, properly understood, must contain, it is perfectly possible for someone to satisfy that test, yet still appear disingenuous to the person they are trying to persuade. There is a crucial distinction, then, between what we might call the fact of disingenuousness and the perception that it obtains. From the strategic perspective of trying to generate support for liberal political values and institutions for the right reasons, it is the latter that is of vital importance.

So, even where the reasoner by conjecture is being sincere in the relevant sense, her intervention might be taken to be disingenuous by the unreasonable. We shall offer four explanations: the perception of bias; the perception of arrogance; the perception of insincerity; and, the perception of a lack of credibility.

\section{The Perception of Bias}

Despite giving assurances of honesty and open-mindedness, the belief that the conjecturers are biased is likely to remain. Given the fact that the liberal is engaging in a deliberate and open attempt to change beliefs, the person who is the target of that attempt may well interpret that instrumental aim as clouding the judgment of the conjecturer. Even if the conjecturer claims to be open-minded and open to having her views changed, the unreasonable might hold the epistemic worry that such bias, whether intentional or unintentional, is unavoidable (see Schwartzman 2012, pp. 531-532). Where the liberal purports to offer an unbiased interpretation of their texts, the unreasonable are simply likely to dispute that such an unbiased view is possible. Some Christian apologists who enter into public debates with non-believers will, for example, debate the existence of a Deity and various scientific and metaphysical claims about the nature of the world and universe, but refuse to debate scriptural or doctrinal issues with non-Christians on the basis that their bias prevents them from engaging genuinely and sincerely with believers. Similarly, although Wong's example of Bernie Sanders has some of the traction it does because of the doctrinal similarities and historical connectedness of Judaism and Christianity. When Sanders reasons from conjecture about what Christians should believe, given

\footnotetext{
${ }^{2}$ See also Scwartzman's (2012) discussion of sincerity and disclosure (esp. 529-532).
} 
the articles of their faith, many Christian listeners would likely perceive less bias in Sanders than, say, if a Muslim or atheist had attempted a similar enterprise. ${ }^{3}$ Here, we should conclude that the intentions of the speaker are not sufficient to allay the charge of disingenuousness. Conversely, an internal engager is less likely to suffer from charges of bias on the grounds of arguing from grounds they do not accept, or from purely instrumental and biased interpretations. Although such charges might be, and no doubt are, levelled against co-religionists, the traction of such accusations is less than it is against outsiders to the shared faith.

\section{The Perception of Arrogance}

The second form of perceived insincerity is that of arrogance. When the conjecturer offers reasons to the unreasonable for thinking they have misunderstood their own faith, the conjecturer runs the risk of being perceived as arrogant or conceited, or possessing a sense of superiority. When politicians state in public what the true meaning of Christianity or Islam is, they can appear crass or rude, as well as condescending, telling those who have spent their lives living the experience of being a Christian or Muslim that they know less about the proper meaning of their faith than someone with little or no comparative experience.

\section{The Perception of Insincerity}

The admission of not sharing the beliefs from which reasoning will begin can, itself, reinforce the perception of insincerity. The conjecturer may be perceived as holding back on what they really think of the unreasonable person's beliefs for the sake of trying to manufacture some kind of political consensus no matter how silly or misguided they do in fact think those beliefs are. Simply adding to this some declaration of honesty about what one actually believes of their interlocutor's view may worsen this perception even further. Someone who says, for example, 'I do not share your belief in reason $R$, and I think there are very good reasons and evidence to think $R$ is false, but if I did believe in $R$, then I would see it as supportive of a liberal political morality on account of considerations $C^{\prime}$, may meet the criteria for honesty and open-mindedness, but may also seem to their interlocutor as lacking even less commitment to the worth of the view they are aiming to engage with.

\section{The Perception of a Lack of Credibility}

Relatedly, when those outside a given religion engage in conjectural reasoning, they may be viewed as lacking sufficient credibility for their arguments to be given any weight or consideration. Perceived disingenuousness in this sense can be seen as

\footnotetext{
3 This may be increasingly the case given a significant movement within (particularly American) evangelical Christianity - so called 'Christian Zionism' - that is supportive of the Jewish state of Israel, and the place of Jews in eschatological views, based on certain (Christian) biblical prophecy.
} 
the conjecturer not having paid her dues in coming to understand and appreciate the faith from within; that they are not native to the faith. This lack of credibility may have several dimensions to it. First, any external interlocutor or conjecturer, however knowledgeable and good her reasoning, may lack credibility, because the particular faith group does not see her intervention as having authority. Many religions contain, as a component of their faith, content-independent reasons for belief, such as deference to de facto intellectual authorities. For example, the Pope is considered by those who follow the doctrines of the Roman Catholic Church as the inerrant voice of theological and moral authority to whom their judgement on certain matters must be surrendered. If such de facto authorities provide reasons for belief that are independent of the content of those beliefs, then conjecturing on the basis of those beliefs will largely miss the point, and will be very unlikely to succeed at persuasion.

Second - and questions of deference to authority aside - the views of some people receive greater attention, or are given greater weight, than the views of others in virtue of their place or role (or lack thereof). For instance, some believe that the views of the devout carry more weight than the views of those who lack faith or revelation. Where this is the case, the person who engages in conjectural reasoning may provide a better or more accurate interpretation of religious scripture or requirements, but will still be viewed as an interloper who is meddling in issues they really do not understand. Issues of standing, like the issue of authority, will turn on reasons for belief that are quite independent of the content of those religious beliefs. ${ }^{4}$

These content-independent reasons notwithstanding, there are several problems with conjecture on content-dependent grounds. To be credible, the conjecturer must surpass some threshold of knowledge or understanding for their arguments to carry any weight with the faithful. Ignorant interventions, or arguments based on what the believer considers to be simple misconstruals of essential points that betoken a lack of understanding or impartiality, are not likely to encourage the taking of the conjecturing seriously. When politicians pronounce on the correct interpretation of a religious view that they quite obviously do not share, they appear disingenuous because of a lack of credibility to make such judgements, even if their verdict happens to be correct.

As Schwartzman notes, one way to respond to the lack of credibility challenge is for the conjecturer to lay out their scholarly credentials (Schwartzman 2012, p. 541). A genuine and concerted effort over an extended period of time to learn about a given faith is about as much as anyone external to the faith can do to gain such credibility. Such knowledge, if necessary for conjecturing is costly to come by, and unlikely to be possessed by politicians and political philosophers. Only a few specialists, such as March's (2009) work on Islam and Rawlsian political liberalism, may exist. Even here, however, this may not be enough for some who hold unreasonable views. It may be objected by the devout that it is impossible to understand

\footnotetext{
${ }^{4}$ One form of example of this kind of rejection is listed by renowned biblical scholar Bart D. Erhman, who reports that a familiar reaction among Christian adherents to his historical research is one of dismissal on the grounds that Erhman himself lacks the necessary faith to be a legitimate authority (Erhman 2010).
} 
their religious view sufficiently without the experience of living as a devout believer oneself. It is sometimes claimed, for example, that it is impossible properly to grasp the Islamic faith without being able to read the Qu'ran in its Arabic form; reading it in translation is insufficient to convey its full and true meaning and import. If this is the view held by the unreasonable, then there is little the external conjecturer can do other than protest that the threshold is set unreasonably high, and that a view that is incapable of being explained to, or learned about to a satisfactory degree, by those not raised in it is hardly a suitable basis for the exercise of public political power (Schwartzman 2012, pp. 541-542). Moreover, we might wonder, in conjectural terms, whether an all-powerful God who deems his message to provide such a basis, is incapable of conveying that message in more than one language. Notwithstanding these replies, however, many unreasonable citizens will be unmoved by them and continue to doubt the credibility of external interlocutors.

\section{Weighing the Costs}

Such challenges - the perceptions of bias, arrogance, sincerity and credibility - are less likely to be faced by those internal to a given religious set of beliefs. Many believers will pass the necessary thresholds to have their arguments considered. This is not, of course, automatically the case. Much that passes as religious debate within a single denomination, such as Protestant Christianity, focuses upon the denunciation of the interlocutor as a heretic or false Christian, despite an apparent acceptance of the major articles of faith. Sometimes the narcissism of small differences can be a greater barrier to persuasion than the differences between faiths (see Stevens and O'Hara 2015, Ch. 4). Our claim is that this is less often the case, and that persuasion from within is, given the non-normative facts in play, more likely to succeed.

In addition, as we suggested above, it is important to consider the costs of persuasion. Even if external reasoning from conjecture could succeed, the considerable costs that would have to be incurred to avoid the problems of bias, arrogance, sincerity and credibility suggest that the rational choice of a liberal community would be to adopt the 'persuasion begins at home' division of labour we propose. Such a division does not necessarily place all the burdens of conjecture on a particular section of the community. In a multicultural society there are very many religious and nonreligious communities, each of which has unreasonable as well as reasonable members. Accordingly, reasonable citizens holding different comprehensive conceptions should discharge their duties of engagement by engaging with those who share some of their comprehensive convictions. In cases in which, because unreasonableness is not evenly distributed between comprehensive doctrines, there exists an inequality of the burdens of persuasion, measures must be put in place to compensate those who take on greater burdens.

Finally, we should note that our argument is not that such persuasion is only possible from within a particular community or religious tradition: that any kind of external attempts, even to persuade members on their own terms, is a kind of cultural imposition that brings values and modes of thought and interaction alien to that tradition. Reasoning from conjecture, properly construed, deliberately refrains 
from arguing against the fundamental starting points, and accepts them for the sake of argument, with the aim of 'clear[ing] up what we take to be a misunderstanding on others' part, and perhaps equally on ours' (Rawls 1999, p. 594). Our objection is not one of principle, but of pragmatism. Internal persuasion is more likely to be effective in achieving the desired end. This would be fully consistent with affirming external conjectural reasoning as the most likely method to succeed in those cases where internal persuasion is impossible or counter-productive. Where individuals internal to the view might face significant personal costs for engaging in such argumentation-perhaps being ostracized, branded as heretics, or worse-or where the views of adherents lack a certain authority in such matters - then conjectural reasoning may be a better method of proceeding (see Schwartzman 2012, p. 539). The kinds of cases we are imagining however-those that are the mainstay of disputes in our own democratic societies_-are not predominantly of this kind.

OpenAccess This article is distributed under the terms of the Creative Commons Attribution 4.0 International License (http://creativecommons.org/licenses/by/4.0/), which permits unrestricted use, distribution, and reproduction in any medium, provided you give appropriate credit to the original author(s) and the source, provide a link to the Creative Commons license, and indicate if changes were made.

\section{References}

Abdullahi Ahmed An-Na'im. 1990. Toward an Islamic reformation: Civil liberties, human rights, and international law. Syracuse, NY: Syracuse University Press.

Clayton, Matthew, and Andres Moles. 2018. Neurointerventions, morality, and children. In Treatment for crime, ed. David Birks, and Tom Douglas. Oxford: Oxford University Press.

Clayton, Matthew, and David Stevens. 2014. When god commands disobedience: Political liberalism and unreasonable religions. Res Publica 20: 65-84.

Dworkin, Ronald. 2011. Justice for hedgehogs. London: Belknap Press.

Erhman, Bart D. 2010. Jesus interrupted: Revealing the hidden contradictions in the Bible (and why we didn't know about them). London: HarperOne.

Hobbes, Thomas. 1991 [1651]. Leviathan, ed. Richard Tuck. Cambridge: Cambridge University Press.

March, Andrew F. 2009. Islam and liberal citizenship: The search for an overlapping consensus. Oxford: Oxford University Press.

Rawls, John. 1996. Political liberalism, Paperback edn. New York, NY: Columbia University Press.

Rawls, John. 1999. The idea of public reason revisited. In John Rawls: Collected papers, ed. Samuel Freeman. Cambridge, MA: Harvard University Press.

Schwartzman, Micah. 2012. The ethics of reasoning from conjecture. Journal of Moral Philosophy 9: 521-544.

Stevens, David, and Kieron O'Hara. 2015. The Devil's long tail: Religious and other radicals in the internet marketplace. Oxford: Oxford University Press.

Wong, Baldwin. 2018. Conjecture and the division of justificatory labour: A Comment on Clayton and Stevens. Res Publica. https://doi.org/10.1007/s11158-017-9373-2.

Publisher's Note Springer Nature remains neutral with regard to jurisdictional claims in published maps and institutional affiliations. 